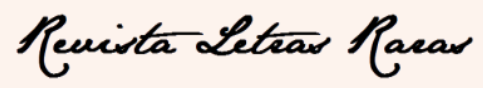

ISSN: 2317-2347 - v. 8, n. 2 (2019)

\title{
DIAS, Cristiane. Análise do discurso digital: sujeito, espaço, memória e arquivo. Campinas: Pontes Editores, 2018. p. 1-202.
}

Rhafaela Rico Bertolino Beriula*

Publicado pela Editora Pontes no ano de 2018, o livro “Análise do Discurso Digital: sujeito, espaço, memória e arquivo", escrito por Cristiane Dias, pesquisadora do Laboratório de Estudos Urbanos - LABEURB/UNICAMP, retrata a expansão da Análise de Discurso (AD) no Brasil, o que leva o leitor a uma interessante leitura sobre o meio digital, o espaço urbano, o político e o sujeito e, como ele - o sujeito - está conectado, literalmente e figurativamente, a todos esses processos, por meio das formas históricas de assujeitamento presentes em nossa sociedade. A leitura do livro provoca reflexões dos atos digitais e dos sentidos produzidos por sujeitos inseridos em uma sociedade capitalista, e de que modo produzem e compartilham a circulação de informações nas redes; ou seja, a maneira que geram a narrativa digital, nas diversas facetas ideológicas e políticas. Assim, o livro corrobora com o entendimento de como os sentidos são constituídos através do discurso digital.

Ao contemplar os aspectos que formam a capa do livro, Cristiane Dias conduz o leitor a perceber as imagens que o constituem, remetendo-se a conceitos que são apresentados no decorrer da leitura. No centro do livro há uma mão - o sujeito - que segura determinado aparelho tecnológico - o recurso digital -, mais precisamente, um smartphone. Na tela do celular há uma foto - que leva o leitor a ver/pensar em outro texto carregado de sentidos -, com a presença de casas e prédios, o que representa o centro urbano - o espaço. Tais efeitos de sentidos produzidos pelas imagens permitem uma préconstituição imaginária da cidade, da história e da memória dos sujeitos que ali vivem e produzem sentidos.

\footnotetext{
* Graduada em Pedagogia pela Universidade do Estado de Mato Grosso (UNEMAT) em 2014, especialista em Docência no Ensino Superior e na Educação de Jovens e Adultos (EJA) pela Faculdade Venda Nova Do Imigrante (FAVENI) em 2017, Mestranda pelo Programa de Pós-Graduação em Letras (PPG Letras) 2018 2020, ofertado pela UNEMAT no Campus Universitário de Sinop. Integrante do Grupo de Pesquisa Educação Científico-tecnológica e Cidadania (ECTeC). Sinop/Mato Grosso/Brasil. E-mail: rhafa_rico@hotmail.com.

Todo o conteúdo da Revista Letras Raras está licenciado sob Creative Commons Atribuição 4.0 Internacional
} 


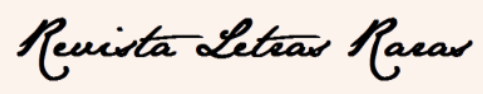

ISSN: $2317-2347$ - v. 8, n. 2 (2019)

Ainda na capa, há uma imagem em plano de fundo - marca d'água -, que pode até passar despercebida, mas ao observá-la, percebe-se o desenho de sujeitos se relacionando com os recursos digitais, isto é, sujeitos que vivem no mesmo espaço dos arquivos digitais. Tal imagem causa a seguinte reflexão: a cidade e os sujeitos não mais podem ser vistos separados da tecnologia? Não. Assim, a cidade é um espaço digital, e passa a ser terminologicamente intitulada de conecticidade.

Em relação aos caminhos trilhados por Cristiane Dias, é perceptível que vem, ao longo dos trabalhos feitos, compreender os efeitos de sentidos que o discurso digital engendra na sociedade e nos sujeitos a qual dela participam. Por esse motivo, estuda e apresenta os resultados acerca das mudanças discursivas que ocorrem no mundo, justamente pelo contínuo avanço das tecnologias digitais. É possível notar que a autora se incomoda com tais processos e mudanças e buscar entendê-los para que o sujeito - a população em geral - não seja apático e estável a elas.

Na primeira parte do livro intitulada: Parte I - Sujeito, Tecnologia e Circulação, Cristiane Dias salienta que, da mesma forma que o discurso na $\mathrm{AD}$ não é transparente, a tecnologia é apresentada como opaca, passível de descobertas de sentidos que são apresentados em diferentes tipos de textos e, relativamente, nos discursos referentes a eles. Assim, apresenta o digital através da discursividade, que só é possível pela circulação, o que ocorre quando o sujeito se apresenta na rede. $O$ ato da circulação também gera deslizamentos de sentidos em determinados e/ou diferentes grupos sociais, o que retoma à constituição do político, uma vez que, através dos discursos postos em rede, outras formas de assujeitamentos se apresentam, mas agora, partem da ordem do digital.

Ao procurar compreender os sentidos determinados pelo simbólico em relação com o político, Cristiane Dias relata que o digital apenas significa através da troca de sentidos, que ocorrem durante o contato com o outro nos relacionamentos que ocorrem em ambientes digitais, ou seja, a partir de aparelhos digitais busca compreender como, por exemplo os smartphones, são e dão significados à sociedade e aos sujeitos. Desta maneira, volta o olhar as redes digitais de organização da memória e do esquecimento, que estão presentes em aplicativos de localização - como, por exemplo, o Google Maps, GPS, e assim por diante -, a aplicativos que organizam o dia a dia das pessoas - agendas digitais, calendários etc. - e, também, os mais utilizados atualmente, os populares aplicativos de relacionamentos - Facebook, Tinder, WhatsApp, entre outros. 


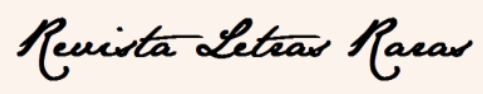

ISSN: $2317-2347-$ v. 8, n. 2 (2019)

A autora aponta que não se pode esquecer que as tecnologias digitais são desenvolvidas por sujeitos que tencionam metas determinadas nas relações de força e poder capitalista, remetendo-se ao assujeitamento. Reflete também sobre os modos de funcionamento do discurso digital, que podem aparecer de forma nociva a vida social do ser humano ou, então, tornar-se a grande ferramenta que condiciona novos relacionamentos e comunicações. Sobre o último ponto, a extensão do digital pode ser ultrapassada, o que conduz os sujeitos a significarem na vida real, mas cabe ao sujeito descobrir quais são os sentidos que as tecnologias digitais o levam a ver, fazer, sentir, compartilhar e digitar. Assim, Cristiane Dias apresenta, diferenciando-se de outros autores, que a tecnologia, mais precisamente o digital, são afetados pela história. Então, se o sujeito é afetado pela constituição ideológica da história, da mesma forma, o digital também é afetado.

$\mathrm{Na}$ Parte II do livro, chamada de "Arquivo, Memória, Espaço", Cristiane Dias aprofunda os vínculos entre sujeito e arquivo e relata que nunca se arquivou tanto. Retoma o debate que introduz na parte I, com a fala de que, atualmente o corpo humano é uma extensão da máquina. Dessa forma, leva o leitor a refletir que está tão ligado a tecnologia que não se pode mais se separar dela. As memórias - um passeio, um sentimento, um trabalho, uma defesa política, entre outros tipos de situações - estão arquivados em rede, passíveis de visualizações e compartilhamentos. Os sujeitos expõem-se em um local que muitos outros sujeitos terão acesso. Então, cabe ao leitor engendrar uma análise dos efeitos que as tecnologias geram no cotidiano da vida humana; ser o sujeito que é/se transforma em arquivo ou o sujeito que extrapola o arquivo.

Sobre a cidade digital, Cristiane Dias apresenta aos leitores movimentos que se originaram nas redes sociais e extrapolaram os sentidos para as ruas, metaforizando-as. Desse modo, propõe um estudo sobre a mobilidade e a $i$-mobilidade - o mover-se entre a conectividade dos sistemas e dispositivos digitais sem sair do local - da cidade e dos movimentos sociais, que ajuda o leitor a compreender que tais movimentos se constituem em materialidade histórica, que afetam ideologicamente os sujeitos que estão inseridos na sociedade. Com isso, a relação do espaço da cidade com o sujeito que convive com o digital, leva a autora a falar sobre conecticidade, ou seja, o alargamento imagético da cidade causado pelo discurso-transverso do digital. 


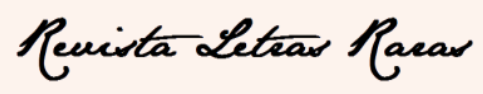

ISSN: $2317-2347$ - v. 8, n. 2 (2019)

Exemplificando a mobilidade e a i-mobilidade, expõe dois sentidos de deslocamento da educação fomentada pela tecnologia. O primeiro sentido é o ato de deslocar a escola para outro local - como por exemplo, deslocá-la à uma plataforma digital -, por mais que se encontre em um 'novo' local, produz o mesmo sentido do local da escola, e, consequentemente, repete a mesma produção de conhecimento que transcorre dentro da escola por meio das disciplinas curriculares. O segundo sentido, compreende em deslocar o processo de ensino-aprendizagem, que ocorre no ambiente escolar, para outros locais não institucionalizados, ou seja, deslocar o sentido de ensinar para outras condições de aprender, sair da zona de divisão e disciplinarização de matérias para aprender com os movimentos sociais e culturais que ocorrem ao longo da extensão da cidade.

Há assim os sentidos da tecnologia voltados à educação e ao urbano que concerne à ordem do político, onde o deslocamento provoca outros sentidos. Assim, constitui-se a articulação vertical do conhecimento e o processo de metaforização em que o ensino e o digital se encontram no urbano para produzir novos processos de significações, desse jeito, deslocam-se novas aprendizagens.

Na última parte do livro, chamada de: Parte III - Política, Língua e Escritura, Cristiane Dias volta a falar sobre a mobilidade e $i$-mobilidade. Direciona o olhar aos atos do dia a dia do sujeito, mais precisamente, o cotidiano ensimesmado que se desenrola/articula devido a utilização maciça dos aplicativos digitais. Com isso, aponta delineamentos acerca do funcionamento da memória e a construção da narratividade presente nas postagens da rede social Facebook, a qual organiza as memórias/postagens em feed de notícias através de algoritmos e cookies - estabelecidos através das postagens e das pesquisas individuais de cada sujeito.

No último capítulo do livro, a autora apresenta também a linguagem na mídia como poder, presente nos discursos políticos e, lança uma reflexão sobre quando, realmente, os políticos falam a língua do povo. Destaca também que, justamente pelo sentido político, a língua se compõe em um lugar de preconceitos, intolerâncias e alienação, e dá como exemplo, as constituições de significados e silenciamentos ocorridos durante a ditadura militar, onde a língua foi silenciada e levada a ser uma 'boa língua'.

Ao falar sobre o silenciamento, traz as dimensões técnicas do silêncio na circulação do contexto digital cotidianamente. Por haver inúmeros aplicativos que ajudam e, de certa forma também tutelam/controlam as ações do sujeito em rede, passam a ser suscetíveis a se 


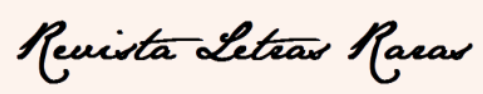

ISSN: $2317-2347$ - v. 8, n. 2 (2019)

tornarem um arquivo uno, passível de silenciamentos de outros sentidos possíveis; ainda mais se observar que, o que geram tais silenciamentos são os padrões identitários produzidos pelo sistema capitalista que utilizam os cliques para ofertar para o mercado, informações, mercadorias e serviços. Assim, o funcionamento do discurso é político e se torna também, pelo digital, mercantilizado.

Para finalizar a reflexão, durante a leitura percebe-se que Cristiane Dias elenca o discurso como objeto teórico e, o digital, é o espaço que possui inúmeros objetos passíveis de análise. Considerado como o campo dos objetos de estudos teóricos e de reflexões, o digital é apresentado em uma perspectiva não só ligada propriamente à tecnologia em si, mas também, como porta de entrada para a circulação dos sentidos; ou seja, a constituição de produção ideológica do político e do sujeito em múltiplos sentidos, que significam e se ressignificam em uma proporção estimulada pelo capitalismo a partir de recursos digitais que levam a outras produções e outros processos de circulação. Gera-se assim, segundo a autora, o ato de formulação de discurso circular, que pode não acontecer em etapas determinadas, mas sempre acontece, se constitui; então, ele é interminável/intermitente.

À vista disso, escreve que o conviver digitalmente é quase automático nos dias de hoje, contudo, essa exposição em massa dos sujeitos aponta fragilidade e riscos. A partir do sujeito que se torna arquivo, Cristiane Dias mostra aos leitores as possibilidades de se tornarem sujeitos que extrapolem o meio digital, sujeitos que vão além das telas e dos cliques sedentários e individualizados, podendo estimular movimentos de aprendizagens, como os que ocorreram nos episódios 'a aula vai ser na rua', produzindo novos deslocamentos de sentidos na conecticidade, ou seja, dar outros sentidos ao digital que, mesmo fora do seu espaço online, significa.

Data de recebimento: 06/02/2019

Data de aceite: $28 / 06 / 2019$ 